\title{
Clinicopathological Study on Endocrine Cell Micronests Associated with Early Gastric Cancer
}

\author{
Kenjiro Suzuki ${ }^{1}$, Yutaka Noda ${ }^{1}$, Naotaka Fujita ${ }^{1}$, Dai Hirasawa ${ }^{1}$, Takashi Obana ${ }^{1}$, \\ Toshiki Sugawara ${ }^{1}$, Tetsuya Ohira ${ }^{1}$, Yoshihiro Harada ${ }^{1}$, Yuki Maeda ${ }^{1}$, Yoshiki Koike ${ }^{1}$, \\ Taku Yamagata ${ }^{1}$, Jun Kusaka ${ }^{1}$, Megumi Tanaka ${ }^{1}$, Takashi Sawai ${ }^{2}$ and Akira Kurose ${ }^{3}$
}

\begin{abstract}
Objective The purpose of this study was to review cases of early gastric cancer associated with Endocrine cell micronests (ECM) and investigate the incidence and characteristics of these lesions.

Methods A total of 482 patients who had undergone endoscopic or surgical resection for gastric epithelial neoplasms from April 2008 to March 2010 were enrolled in this study. After detection of ECM in the lamina propria mucosa by histological examination of the resected specimens with hematoxilin-eosin staining, immunostaining was also performed. Clinical manifestation and endoscopic findings, as well as histological findings, were examined.

Results Among the 482 patients, 5 (1.0\%) had ECM. The histological type of gastric epithelial cancers associated with ECM was tubular adenocarcinoma and carcinoma in situ (Tis) in the WHO classification in all 5 cases. ECM were round to oval or trabecular and located within the area of the early gastric cancer in all the 5 cases. The background gastric mucosa was Type A gastritis in 2 patients and ordinary atrophic gastritis in 2 patients. In the other case, it was difficult to determine the type of gastritis.

Conclusion ECM developed not only from the background of Type A gastritis but also from ordinary atrophic gastritis. ECM coexistent with gastric cancer were present in $1.0 \%$ of resectable gastric epithelial neoplasms.
\end{abstract}

Key words: endocrine cell micronests, early gastric cancer, development of ECM, type A gastritis, ordinary atrophic gastritis

(Intern Med 52: 1311-1316, 2013)

(DOI: 10.2169/internalmedicine.52.9229)

\section{Introduction}

Endocrine cell micronests (ECM) are clusters of endocrine cells seen in the deep layer of the lamina propria mucosa. ECM are precursors of carcinoid tumors and often present around such tumors. Cases of carcinoid coexistent with gastric cancer have often been reported, but the developmental process has not been clarified. In addition, there have been very few reports on cases of only ECM, not carcinoid, coexistent with gastric cancer, and the incidence, characteristics, and developmental process of ECM coexistent with gastric cancer are not well known.

ECM develop from hyperplasia of endocrine cells contained in the mucosa of the atrophic fundic glands and pyloric glands. Most reported ECM have a background of Type A gastritis. However, it is also known that multiple ECM can develop in the absence of a carcinoid tumor in ordinary atrophic gastritis, without Type A gastritis $(1,2)$. The developmental process of ECM of this type has not been well clarified.

We investigated gastric epithelial neoplasms which had been resected endoscopically or surgically as to the coexsistence of ECM and attempted to elucidate the incidence and

${ }^{1}$ Department of Gastroenterology, Sendai City Medical Center, Japan, ${ }^{2}$ Department of Pathology, Iwate Medical University, Japan and ${ }^{3}$ Department of Pathology, Hirosaki University, Japan

Received for publication October 30, 2012; Accepted for publication February 12, 2013

Correspondence to Dr. Kenjiro Suzuki, suzuken@openhp.or.jp 
characteristics of ECM coexistent with gastric cancer.

\section{Materials and Methods}

This study involved 482 cases of gastric epithelial neoplasms in invasion depth was the mucosa or the submucosal layer resected by endoscopic or surgical resection between April 2008 and March 2010 at our institution. Also, these cases were randomized continuation cases. First, detection of ECM in the deep layer of the lamina propria mucosa in resected specimens, stained by hematoxylin-eosin, was attempted. When recognized, we performed the following types of immunostaining. The antisera used were Chromogranin A (NICHIREI BIOSCIENCES), Synaptophisin (Novocastra), Neural cell adhesion molecule (NCAM, Novocastra), Somatostatin receptor subtype 2A (SSTR2A, Gramsch Laboratories), Somatostatin receptor subtype 2A (SSTR5, Gramsch Laboratories), Ki-67 (DAKO), p53 (NICHIREI BIOSCIENCES), serotonin (NICHIREI BIOSCIENCES), gastrin (NICHIREI BIOSCIENCES), insulin (NICHIREI BIOSCIENCES), Adrenocorticotropic hormone (ACTH, NICHIREI BIOSCIENCES), Vasoactive intestinal peptide (VIP, NICHIREI BIOSCIENCES), somatostatin(NICHIREI BIOSCIENCES), Pancreatic polypeptide (PP, NICHIREI BIOSCIENCES), calcitonin (NICHIREI BIOSCIENCES), and glucagon (NICHIREI BIOSCIENCES).

We explored hyperplasia of endocrine cells and the distribution of ECM by Chromogranin A staining for all sections of the gastric epithelial neoplasms and sections of the neighboring non-neoplastic regions. The other immunostainings were performed for the section in which the emergence of ECM was most remarkable. Patient demographics, endoscopic findings, histological findings, and serological tests after treatment were investigated.

\section{Results}

\section{Patient demographics}

In total, 5 of 482 cases $(1.0 \%)$ resected by endoscopic or surgical resection, 3 men and 2 women, were diagnosed as having early gastric cancer with ECM. The mean age of the patients was $70.4 \pm 10.4$ years.

\section{Endoscopic findings}

The location of early gastric cancer with ECM was the fundus in 2 cases, the corpus in 2 , and the antrum in 1 . The circumferential location of the 5 cases was the lesser curvature in 2 , the anterior wall in 2 , and the posterior wall in 1 . No lesion was located in the greater curvature. The mean lesion size was $19 \mathrm{~mm}$ (range 12-30 mm). According to the Paris endoscopic classification, the macroscopic type of tumor was Type 0-IIa (superficial elevated) in 4 cases and type 0-IIc (superficial depressed) in 1 . The color of the lesions showed a similar tendency, i.e., all cases presented discoloration. In terms of atrophy of the background mucosa, all cases showed extensive atrophy involving the whole stomach, including the antrum.

On the other hand, endoscopic findings of gastric epithelial neoplasm without ECM in 477 cases were as follows. The location of the lesion was the fundus in 79 cases, the corpus in 58, and the antrum or the pylorus in 340 . The circumferential localization of these lesions was the lesser curvature in 189 cases, the greater curvature in 90, the anterior wall in 99, and the posterior wall in 99. Many lesions were located in the antrum or pylorus and the lesser curvature. The mean lesion size in these cases was $23 \mathrm{~mm}$ (range 1.4$110 \mathrm{~mm}$ ). The macroscopic type of the lesions was Type 0-I (protruded) in 25 cases, Type 0-IIa in 164 cases, Type 0-IIb (flat) in 10 cases, and Type 0-IIc in 278 cases. As for the color of the lesions, 303 were reddish lesions and 174 showed discoloration (Table 1).

\section{Histological findings}

All cases of gastric epithelial neoplasm with ECM were tubular adenocarcinoma and carcinoma in situ (Tis) in the WHO classification. Diffuse hyperplasia of endocrine cells was found in a part of the tumor in all cases. Hyperplasia was not found in the non-neoplastic area. ECM was present in the deep layer of the lamina propria where diffuse hyperplasia of endocrine cells was seen, and the locations of the diffuse hyperplasia and ECM were almost the same (Fig. 1). In other words, the location of ECM was confined within the early gastric cancer in all cases (Fig. 2). Transition from hyperplasia of endocrine cells to ECM was confirmed (Fig. 3).

The results of immunostaining of the ECM were as follows. The cells composing ECM were stained positively by chromogranin A in all cases. The Ki-67 labeling index was less than $1 \%$ and p53 immunostaining was negative in all cases. Serotonin-positive cells were diffusely found in all cases and gastrin-positive cells were found in some parts of the specimens of Cases 1. The correlation between serum gastrin level and results of immunostaining of gastrin was not confirmed.

As for morphology and shape of ECM, the ECM showed a round to oval structure and a trabecular structure (Fig. 4). The patient demographics and endscopic findings are shown in Table 2.

\section{Serological tests}

A summary of the data on serum anti-helicobacter pylori IgG antibody (H. pylori IgG antibody), gastrin, serotonin, antiparietal cell antibody (PCA) levels, and pepsinogen-I and pepsinogen-II is presented in Table 4. PCA was positive in 3 cases (Cases 2, 3, and 5). Among these 3, elevation of the serum gastrin level was observed in 2 (Cases 3 and 5). In Cases 1 and 4, PCA was negative and the serum gastrin level was low. H. pylori IgG antibody and pepsinogen showed positive in both of these cases (Table 3 ). 
Table 1. Demographics and Endoscopic Findings

\begin{tabular}{lcc}
\hline & Gastric epithelial neoplasm with ECM & Gastric epithelial neoplasm without ECM \\
\hline patients & 5 & 477 \\
Age, years, mean \pm SD & $70.4 \pm 10.4$ & $70.6 \pm 7.9$ \\
Sex & & 350 \\
Male & 3 & 127 \\
Female & 2 & \\
Location of gastric cancer & & 79 \\
Fundus & 2 & 58 \\
Corpus & 2 & 340 \\
antrum & 1 & 189 \\
Circumferential location & & 90 \\
Lesser curvature & 2 & 99 \\
Greater curvature & 0 & 99 \\
Anterior wall & 2 & $23(1.4-110)$ \\
Postrior wall & 1 & \\
Size of gastric cancer, meas, (range) & $19(12-30)$ & 25 \\
Macroscopic type & & 164 \\
0-I (protruded) & 0 & 10 \\
0-IIa & 4 & 278 \\
0-IIb & 0 & 303 \\
0-IIc & 1 & 174 \\
Color & & \\
red & 0 & \\
discoloration & 5 & \\
\hline & & \\
& &
\end{tabular}
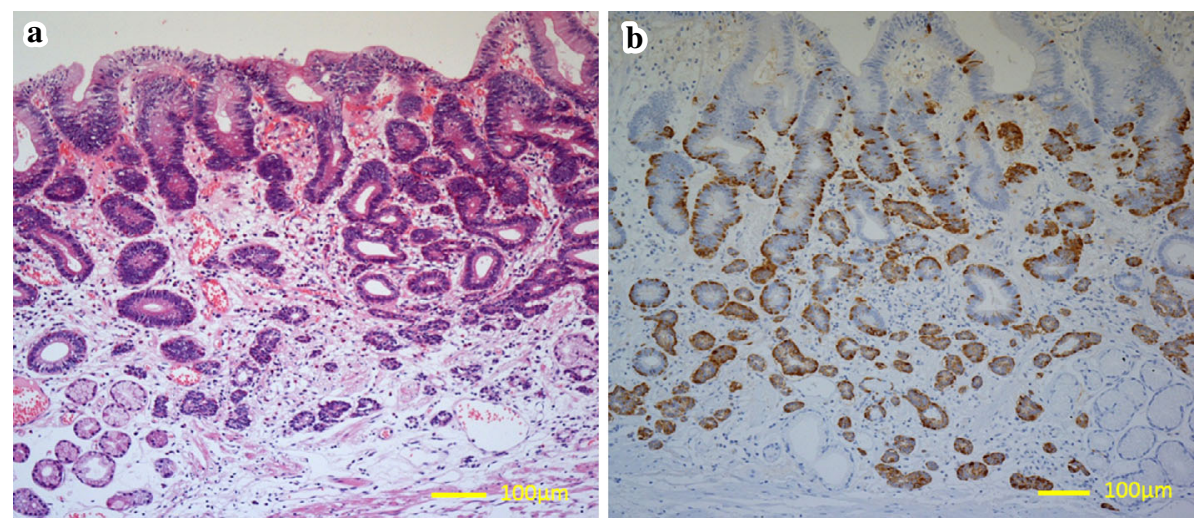

Figure 1. (a) Adenocarcinoma is seen in the upper layer of the lamina propria mucosa in which there is diffuse spreading of ECMs in the deep layer (Hematoxylin and Eosin staining). (b) ECM exist in the layer deeper than the layer of endocrine cell hyperplasia (Chromogranin A stain).

\section{Discussion}

Several kinds of endocrine cells including enterochromaffin cells (EC cells), enterochromaffin-like cells (ECL cells), $\mathrm{G}$ cells, and D cells are present in human gastric mucosa (3-5). Each endocrine cell type secretes a peculiar gastrointestinal hormone, and its distribution domain of the stomach is different. Such endocrine cells develop clusters or hyperplasia, resulting in the development of ECM and microcarcinoids. Furthermore, such ECM and microcarcinoids become neoplastic, leading to the formation of carcinoids.
Rindi et al. classified gastric carcinoids into three types (6-8). Carcinoid with type A gastritis is the most frequent of the three types, reportedly accounting for $65 \%$ (9).

There are two different types of chronic atrophic gastritis, one is ordinary atrophic gastritis in which atrophy is severer in the pyloric gland mucosa than in the fundal gland mucosa, and the other is type A gastritis in which atrophy is severer in the fundal gland mucosa than in the pyloric gland mucosa. Strickland et al. (10). classified the former type as type B gastritis and the latter as type A gastritis. They emphasized the absence of damage on the antral mucosa and presence of PCA to be the most characteristic histological findings of type A gastritis. The developmental mechanism 

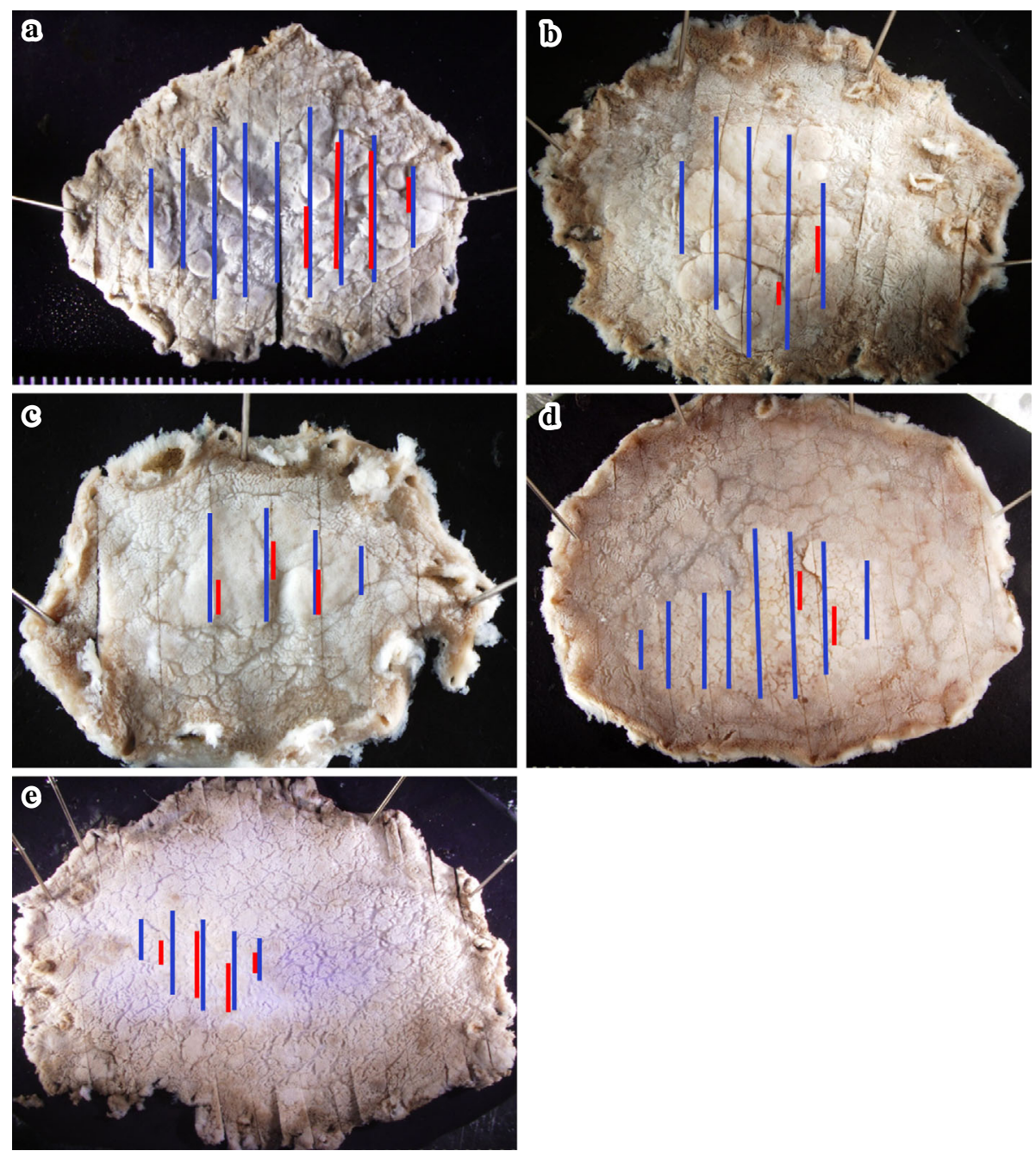

Figure 2. Distribution of ECM and early gastric cancer in resected specimens. Red lines show the area of ECM, and blue lines show the area of early gastric cancer. Distribution of ECM was limited in the area of early gastric cancer in all cases. (a) Case1. (b) Case 2. (c) Case 3. (d) Case 4. (e) Case 5.

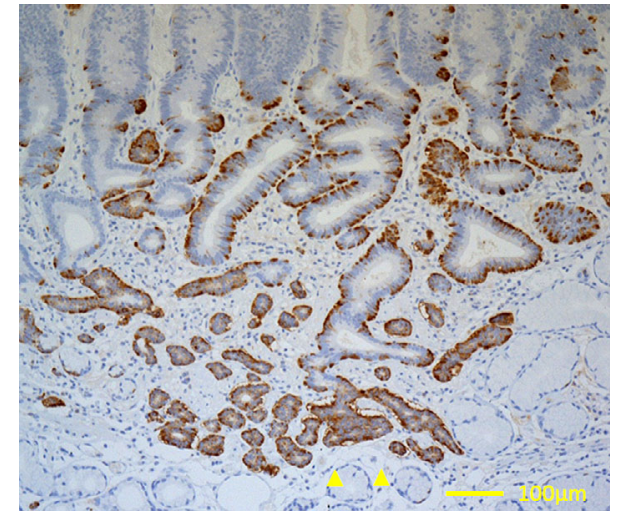

Figure 3. Transition from endocrine cell hyperplasia to ECM (arrows).

of ECM and carcinoid in type A gastritis is well known (11). On the other hand, there has been reports addressing the fact that multiple ECM can develop in ordinary atrophic gastritis without Type A gastritis. However the role of atrophy in the development of ECM has not been clari- fied $(1,2)$. In the present study, atrophy was remarkable in the entire stomach, including the antrum, in all cases. In Cases 2, 3 and 5, PCA was positive, whereas in Cases 3 and 5, serum $H$. pylori IgG antibody was negative and serum gastrin level was slightly elevated, $400 \mathrm{pg} / \mathrm{mL}$ and $260 \mathrm{pg} /$ $\mathrm{mL}$, respectively. Although the serum gastrin level was not as high as that observed in typical type A gastritis, these two cases were considered to have type A gastritis. On the other hand, in Case 2, PCA and serum H. pylori IgG antibody were positive, whereas the serum gastrin level was in the normal range. Therefore, it was difficult to determine the diagnosis of gastritis in this case. Cases 1 and 4 showed negative PCA and positive serum $H$. pylori IgG antibody. As for serum gastrin level, extremely mild elevation was found in Case 1, and the level was within the normal range in Case 4. The results of these two cases suggest that they had ordinary atrophic gastritis.

The results of the present study suggest that there are ECM-associated early gastric cancer not only with type A gastritis but also with ordinary atrophic gastritis. In other words, it is very likely that early gastric cancer played some 

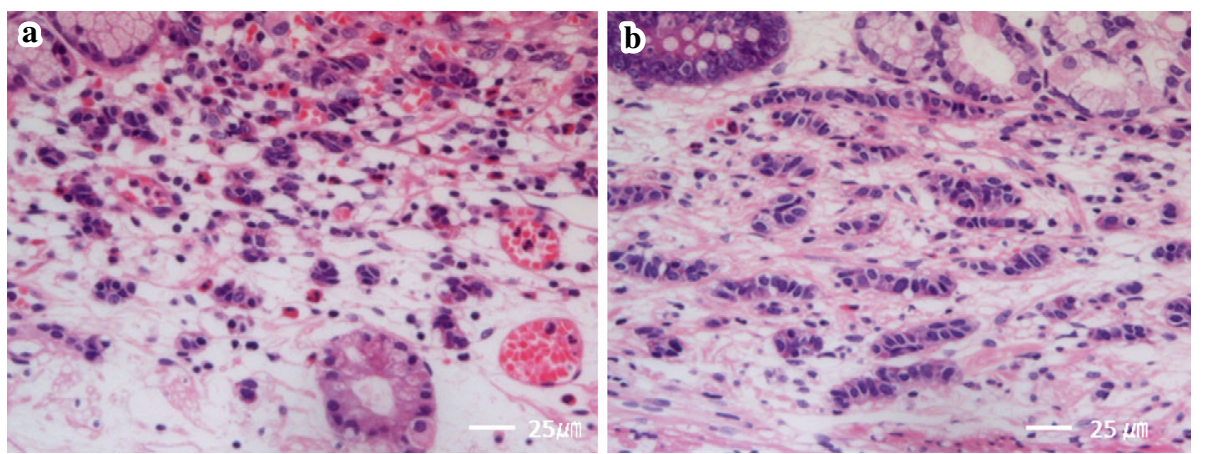

Figure 4. (a) ECM showing round to oval structures (Hematoxylin and Eosin staining). (b) ECM forming trabecular structures (Hematoxylin and Eosin staining).

Table 2. Histopathological Findings

\begin{tabular}{|c|c|c|c|c|c|}
\hline & Case 1 & Case 2 & Case 3 & Case 4 & Case 5 \\
\hline \multicolumn{6}{|l|}{ Cancer } \\
\hline Histology & $\mathrm{TA}$ and $\mathrm{Ca}$ in situ & $\mathrm{TA}$ and $\mathrm{Ca}$ in situ & $\mathrm{TA}$ and $\mathrm{Ca}$ in situ & $\mathrm{TA}$ and $\mathrm{Ca}$ in situ & $\mathrm{TA}$ and $\mathrm{Ca}$ in situ \\
\hline \multicolumn{6}{|l|}{$\mathrm{ECM}$} \\
\hline Chromogranin A & + & + & + & + & + \\
\hline Synaptophisin & - & + & + & + & + \\
\hline NCAM & - & - & $+(\mathrm{f})$ & $+(\mathrm{f})$ & - \\
\hline SSTR2A & $+(\mathrm{d})$ & $+(\mathrm{d})$ & - & $+(\mathrm{d})$ & - \\
\hline SSTR5 & - & - & - & - & - \\
\hline Ki67 & $<1 \%$ & $<1 \%$ & $<1 \%$ & $<1 \%$ & $<1 \%$ \\
\hline P53 & - & - & - & - & - \\
\hline Gastrin & $+(\mathrm{f})$ & - & - & - & - \\
\hline Serotonin & $+(\mathrm{d})$ & $+(\mathrm{d})$ & $+(\mathrm{d})$ & $+(\mathrm{d})$ & $+(\mathrm{d})$ \\
\hline Insulin & - & - & - & - & - \\
\hline $\mathrm{ACTH}$ & $+(\mathrm{f})$ & - & - & - & - \\
\hline VIP & $+(\mathrm{f})$ & - & - & - & - \\
\hline Somatostatin & $+(\mathrm{f})$ & $+(\mathrm{f})$ & $+(\mathrm{f})$ & - & - \\
\hline PP & $+(\mathrm{f})$ & $+(\mathrm{f})$ & - & - & - \\
\hline Calcitonin & - & - & - & - & - \\
\hline Glucagon & $+(\mathrm{f})$ & - & - & - & - \\
\hline Structure & $\begin{array}{l}\text { Round to oval and } \\
\text { trabecular }\end{array}$ & Trabecular & Round to oval & $\begin{array}{l}\text { Round to oval and } \\
\text { trabecular }\end{array}$ & $\begin{array}{l}\text { Round to oval and } \\
\text { trabecular }\end{array}$ \\
\hline Diameter $(\mu \mathrm{m})$ & 110 & 120 & 130 & 260 & 140 \\
\hline Depth & Lamina propria & Muscularis mucosa & Lamina propria & Lamina propria & Lamina propria \\
\hline
\end{tabular}

TA: Tubular adenocarcinoma, Ca: Carcinoma, ECM: Endocrine cell micronests, NCAM: Neural cell adhesion- molecule, SSTR2A: Somatostatin receptor subtype 2A, SSTR5: Somatostatin receptor subtype 5, (d): diffse,

(f): focal, ACTH: Adrenocorticotropic hormone, VIP: Vasoactive intestinal peptide, PP: Pancreatic polypeptide

important role in the development with ordinary atrophic gastritis.

As for the developmental process of ECM in these five cases, we speculate that ECM are formed by budding of clusters of hyperplastic endocrine cells and their separation based on the following findings: (1) ECM and endocrine cell hyperplasia were limited to within the area of adenocarcinoma, and not seen in neighboring non-neoplastic area. (2) Distribution of ECM was almost concordant with endocrine cell hyperplasia. (3) Transition from endocrine cell hyperpla- sia to ECM was confirmed.

It is well known that carcinoids are often accompanied by other malignant tumors. Concerning gastric carcinoids, there has been a considerable number of cases with gastric cancer, most of which had a background of type A gastritis. In such cases, it is speculated that carcinoid tumors originate from a part of multiple ECM which have developed on the basis of type A gastritis. In other words, the ECM which spread around the carcinoid in the resected specimen do not cause malignant transformation. Considering these facts, ECM can 
Table 3. Serological Tests and Antral Mucosal Damages

\begin{tabular}{|c|c|c|c|c|c|}
\hline & Case 1 & Case 2 & Case 3 & Case 4 & Case 5 \\
\hline HP antibody & + & + & - & + & - \\
\hline PCA & - & + & + & - & + \\
\hline $\begin{array}{l}\text { Serum-gastrin } \\
(40-200 \mathrm{pg} / \mathrm{mL})\end{array}$ & 210 & 140 & 400 & 140 & 260 \\
\hline $\begin{array}{l}\text { Serum-serotonin } \\
(57-230 \mathrm{pg} / \mathrm{mL})\end{array}$ & 90 & 104 & 98 & 112 & 64 \\
\hline Antral mucosal damage & + & + & + & + & + \\
\hline pepsinogen-I & 4.4 & 23.3 & 4.7 & 33.3 & 35.5 \\
\hline pepsinogen-II & 5.7 & 14.1 & 7.0 & 16.8 & 7.1 \\
\hline $\mathrm{P}-\mathrm{I} / \mathrm{II}$ ratio & 0.8 & 1.7 & 0.7 & 2.0 & 5.0 \\
\hline
\end{tabular}

HP antibody: serum anti-helicobacter pylori IgG antibody, PCA: antiparietal cell antibody

be classified into two categories, neoplastic ECM and nonneoplastic ECM $(12,13)$. Itsuno et al. referred to the following findings as the characteristics of neoplastic ECM: (1) ECM measuring $0.1 \mathrm{~mm}$ or greater in the largest diameter. (2) ECM, even if it is less than $0.1 \mathrm{~mm}$ in diameter, infiltrating into the muscularis mucosae or the submucosa. (3) $\mathrm{ECM}$, even if it is less than $0.1 \mathrm{~mm}$ in diameter, composed of large cells with atypical nuclei (12).

Unique observations in the present study are the coexistence of early gastric cancer and ECM with ordinary atrophic gastritis that is not type A gastritis, and the presence of only ECM, not carcinoid tumors. The developmental mechanism of ECM in cases with ordinary atrophic gastritis has not been elucidated. Besides, there have been very few reported cases of gastric carcinoid or ECM associated with early gastric cancer without type A gastritis (11). It is speculated that certain factors are necessary to cause trophic action for endocrine cells to form clusters or to develop hyperplasia in cases of ordinary atrophic gastritis. In our study, the distribution of ECM was limited to the area of gastric cancer in all cases. This observation suggests the possibility that early gastric cancer plays some role in the development of ECM. In addition, the size of ECM was larger than 0.1 $\mathrm{mm}$ in largest diameter in all five cases. In particular, Case 2 showed partial invasion of the lamina muscularis mucosae, which may suggest the potential of these lesions to become carcinoid tumors. These findings may indicate an initial stage of a carcinoid coexistent with early gastric cancer.

In conclusion, ECM developed not only from the background of Type A gastritis but also from ordinary atrophic gastritis, which coexistent with gastric cancer were present in $1.0 \%$ of resectable gastric epithelial neoplasms.

The authors state that they have no Conflict of Interest (COI).

\section{Acknowledgement}

We thank Mr. Thomas Mandeville for assisting with the preparation of the manuscript.

\section{References}

1. Stachura J, Krause WJ, Ivey KJ. Ultrastructure of endocrine-like cells in lamina propria of human gastric mucosa. Gut 22: 534-541, 1981.

2. Shimoda T, Tanoue S, Ikegami M, Fujii Y, Muroya T, Ishikawa E. A histopathological study of diffuse hyperplasia of gastric argyrophil cells. Acta Pathol Jpn 33: 1259-1267, 1983.

3. Solcia E, Capella C, Buffa R, Usellini L, Frigerio B, Fontana P. Endocrine cells of the gastrointestinal tract and related tumors. Pathobiol Ann 9: 163-204, 1979.

4. Solicia E, Polak JM, Pearse AGE, et al. Lausanne 1977 classification of gastroenteropancreatic endocrine cells. In: Gut Hormones. Bloom SR, Ed. Churchill Livingstone, Edinburgh, 1978: 40-48.

5. Solicia E, Capella C, Vassallo G, Buffa R. Endcrine cells of the gastric mucosa. Int Rev Cytol 42: 223-286, 1975.

6. Rindi G, Luinetti O, Cornaggia M, Capella C, Solicia E. Three subtypes of gastric argyrophil carcinoid and the gastric neuroendocrine carcinoma: A clinicopathologic study. Gastroenterology 104: 994-1006, 1993.

7. Rindi G, Bordi C, Rappel S, La Rosa S, Stolte M, Solcia E. Gastric carcinoids and neuroendocrine carcinomas: Pathogenesis, pathology and brhavior. World J Surg 20: 168-172, 1996.

8. Rindi G, Azzoni C, La Rosa S, et al. ECL cell tumor and poorly differentiated endocrine carcinoma of the stomach: Prognostic evaluation by pathological analysis. Gastroenterology 116: 532$542,1999$.

9. Ahlman H, Kolby L, Lundell L, et al. Clinical management of gastric carcinoid tumor. Digestion 55 (suppl. 3): 77-85, 1994.

10. Strickland RG, Mackay IR. A reappraisal of the nature and significance of chronic gastritis. Am J Dig Dis 18: 426-440, 1973.

11. Ambe K, Mori M, Enjoji M. Early gastric carcinoma with multiple endocrine cell micronests. Am J Surg Pathol 11: 310-315, 1987.

12. Itsuno $M$, Watanabe $H$, Iwafuchi $M$, et al. Multiple carcinoids and Endocrine cell micronests in type A gastritis. Cancer 63: 881-890, 1989.

13. Noda $\mathrm{Y}$, Watanabe $\mathrm{H}$, Iwafuchi $\mathrm{M}$, et al. Carcinoids and endocrine cell micronests of the minor and major duodenal papillae. Cancer 70: 1852-1833, 1992.

(C) 2013 The Japanese Society of Internal Medicine http://www.naika.or.jp/imonline/index.html 